\title{
Sudden Respiratory Failure in a Patient with Cushing's Syndrome
}

\author{
Sara Lemoinne ${ }^{1}$, Jean- Luc Baudel ${ }^{1}$, Arnaud Galbois ${ }^{1}$, Georges Offenstadt ${ }^{1,2}$ and Eric Maury ${ }^{*}, 1,2$ \\ ${ }^{1}$ Réanimation Médicale, Université Pierre et Marie Curie-Paris 6, France \\ ${ }^{2}$ INSERM, UMR-S 707; APHP, Hôpital Saint Antoine, F-75012, Paris, France
}

\begin{abstract}
A 79 year-old patient with prostate cancer related Cushing's syndrome was referred to ICU for acute respiratory distress occurring two days after introduction of mifepristone. Pneumocystis jirovecii pneumonia was diagnosed. Despite anti pneumocystis therapy and supportive treatment, the patient died of multiple organ failure. The relationship between mifepristone and Cushing's syndrome and potential implications are discussed.
\end{abstract}

Keywords: Acute respiratory failure, Pneumocystis jiroveci, steroids, Cushing's syndrome.

Cushing's syndrome is a classical but rare disease resulting from exposure to excessive concentrations of glucocorticoid. When surgery is not feasible medical therapy should be discussed. A 79 year-old man was admitted to intensive care unit for acute respiratory distress. He had been treated for prostate cancer for 12 years, with radiotherapy and hormonotherapy. The last prostate-specific antigen (PSA) level was $(0,24 \mathrm{ng} / \mathrm{ml})$ while pelvis MRI disclosed irregular prostate consistent with radiotherapy after-effects without any sign of recurrence of malignancy. He was referred 3 months before to the general ward because of depression, severe systemic hypertension, hypokalaemia and diabetes mellitus. Endogenous hypercortisolism was diagnosed. Static and dynamic analysis: [plasma cortisol level at $8 \mathrm{am}: 1564 \mathrm{nmol} / 1$ (normal $<200 \mathrm{nmol} / \mathrm{l})$, 24h urinary free cortisol excretion: $20200 \mathrm{nmol} / 24 \mathrm{~h}$ (normal $<270 \mathrm{nmol} / 24 \mathrm{~h}$ ), no suppression of plasma cortisol with low dose of dexamethasone, adrenocorticotropic hormone (ACTH) : $145 \mathrm{ng} / \mathrm{l}$.(normal $<50 \mathrm{ng} / \mathrm{l})]$ were in favour of an $\mathrm{ACTH}$ dependent Cushing's syndrome. Considering normal pituitary MRI, final diagnosis was paraneoplastic Cushing's syndrome. CT scan imaging of the thorax (Fig. 1), abdomen and pelvis disclosed bilateral adrenal hyperplasia but did not show any thoracic or pancreatic tumours which are the most common tumours responsible for ectopic ACTH secretion.

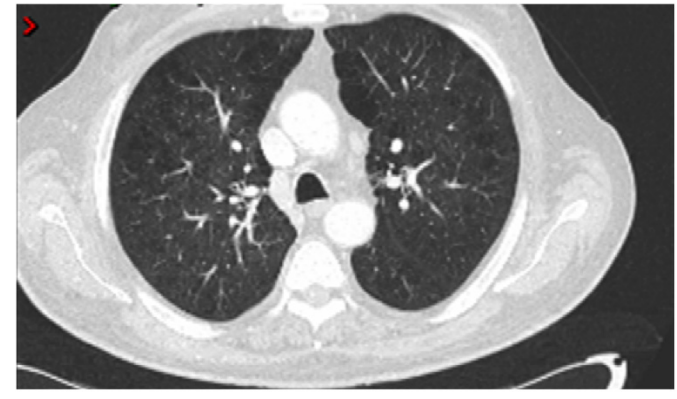

Fig. (1). CT scan of the thorax before pneumoniae, searching for a chest tumor secreting ACTH.

*Address correspondence to this author at the Service de Réanimation Médicale, Hôpital Saint-Antoine, Assistance Publique-Hôpitaux de Paris, 184 rue du Faubourg Saint-Antoine, 75571 Cedex 12, Paris, France; Tel: 33 (1) 492823 18; Fax: 33 (1) 492821 45;

E-mail: eric.maury@sat.ap-hop-paris.fr
The patient was given mifepristone (a potent glucocorticoid receptor antagonist [1]). On the second day of this treatment, the patient complained of shortness of breath ang cough. Temperature was $38,6,{ }^{\circ} \mathrm{C}$, respiratory rate was $35 /$ minute, blood pressure was $120 / 72 \mathrm{mmHg}$. Physical examination was unmodified except for bilateral crackles. Arterial blood gases on room air were: $\mathrm{pH}=7.38, \mathrm{PaO} 2=37$ $\mathrm{mmHg}, \mathrm{PaCO} 2=40 \mathrm{mmHg}, \mathrm{HCO} 3=28 \mathrm{mmol} / \mathrm{L}$. Chest X-ray and CT scan showed bilateral interstitial infiltrates (Fig. 2). The white cell count was $4750 / \mathrm{mm} 3$, lymphocyte count was 630/ mm3, (CD4:29/ mm3). Screening for HIV was negative. The patient was admitted to intensive care unit. A fiberoptic bronchoscopy was performed. Examination of the bronchoalveolar lavage disclosed no bacterial strain but Pneumocystis jiroveci was detected by immunoflorescence. Despite supplemental oxygen the patient had to be intubated and placed on mechanical ventilation. Intravenous sulfamethoxazole and trimethoprime $100 \mathrm{mg} / \mathrm{kg} / 24 \mathrm{~h}$ and 20 $\mathrm{mg} / \mathrm{kg} / 24 \mathrm{~h}$ respectively and methylprednisolone $240 \mathrm{mg}$ daily during 3 days were begun. Mifepristone was stopped. Despite this treatment and supportive care, respiratory status did not improve. The patient developed $P$. aeruginosa pneumonia, multiple organ failure occurred finally died eleven days after ICU admission.

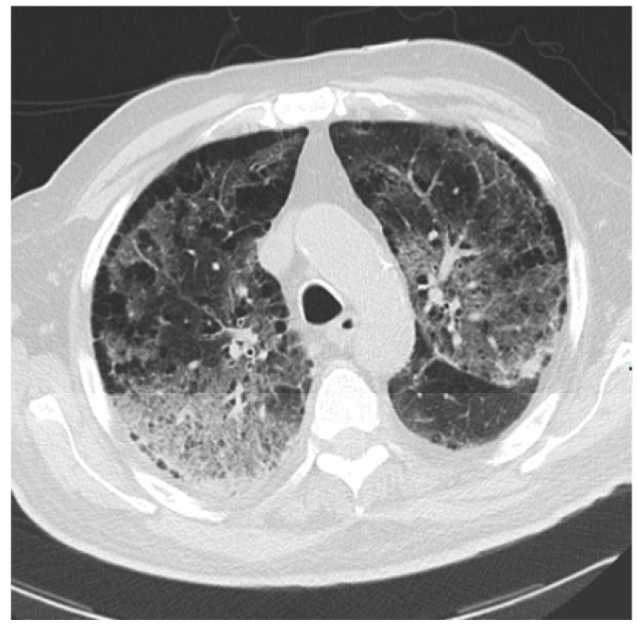

Fig. (2). CT scan of the thorax performed two days after the acute respiratory distress onset. 
The post-mortem examination did not found any other malignancy than prostate cancer.

Pneumocystis jiroveci pneumonia has previously been reported in patients with Cushing's syndrome [2]. Asymptomatic carriage of pulmonary Pneumocystis jiroveci has been observed in animals following long term corticoid treatment. This suggests a potential interest for primary prophylaxis towards Pneumocystis jiroveci in these patients.

The second remarkable issue of this case is that Pneumocystis jiroveci pneumonia seems to have been abruptly triggered by mifepristone treatment. Pneumocystis jiroveci pneumonia has already been reported in patients with Cusing's syndrome following therapy using mifepristone [3] or other cortisol lowering agents [4], and sometimes could occur in such abrupt and severe presentation $[5,6]$. It can be hypothesized that mifepristone suddenly suppressed the anti-inflammatory glucocorticoids effects and restored the immune system similarly to what has been observed in AIDS patients starting on HAART [7]. Clinicians should be aware of this potential complication in patients with Cushing's syndrome.

\section{REFERENCES}

[1] Johanssen S, Allolio B. Mifepristone (RU 486) in Cushing's syndrome. Eur J Endocrinol 2007; 157: 561-9.

[2] Graham BS, Tucker WS. Opportunistic infections in endogenous Cushing's syndrome. Ann Intern Med 1984; 101: 334-8.

[3] Oosterhuis JK, van den Berg G, Monteban-Kooistra WE, et al. Life-threatening Pneumocystis jiroveci pneumoniae following treatment of severe Cushing's syndrome. Neth J Med 2007; 65: 215-7.

[4] Keenan N, Dhillo WS, Williams GR, Todd JF. Unexpected shortness of breath in a patient Cushing's syndrome. Lancet 2006; 367: 446

[5] Kim DS, Park SK, Choi WH, et al. Pneumocystis carinii pneumonia associated with a rapid reduction of cortisol level in a patient with ectopic ACTH syndrome treated by octreotide and ketoconazole. Exp Clin Endocrinol Diabetes 2000; 108: 146-50.

[6] McQuillen DP, Hesketh PJ, Sugar AM. Pneumocystis carinii pneumonia complicating somatostatin therapy of Cushing's syndrome in a patient with metastatic pancreatic islet cell carcinoma and Zollinger-Ellison syndrome. Am J Gastroenterol 1991; 86: 512-4.

[7] Wu AK, Cheng VC, Tang BS, et al. The unmasking of Pneumocystis jiroveci pneumoniae during reversal of immunosuppression: case reports and litterature review. BMC Infect Dis 2004; 4: 57 . 